\title{
SOCIABILIDADE VIOLENTA: por uma interpretação da criminalidade contemporânea no Brasil urbano
}

\section{Luiz Antonio Machado da Silva*}

A violência se liberou de qualquer fundamento ideológico.

Hans M. Enzensberger

(...) o historiador de costumes obedece a leis mais duras do que as que regem o historiador de fatos; aquele deve tornar tudo provável, até o verdadeiro, ao passo que no domínio da história propriamente dita, o impossível é justificado pela razão de ter acontecido.

Honoré de Balzac

Resumo: O ensaio analisa uma das formas de organização social das relações de força que são legal e administrativamente definidas como crime comum violento, tal como aparecem nas grandes cidades, com ênfase para o Rio de Janeiro. A abordagem proposta implica considerar a relação entre a produção simbólica e certas práticas sociais em sua concretude e singularidade mais imediata. Para efeitos da argumentação desenvolvida, o texto, ao esboçar a noção de sociabilidade violenta, busca captar a natureza e o sentido da radical transformação de qualidade das relações sociais a partir das práticas de criminosos comuns, mudança que a produção sociológica tem tido enorme dificuldade em apreender.

Palavras-chave: sociabilidade violenta, crime comum violento, violência urbana como representação social.

* Professor do Departamento de Sociologia do IUPERJ/UCAM e IFCS/UFRJ.

Artigo recebido em 05 jan. 2004; aceito em 10 jun. 2004. 


\section{Introdução}

Este ensaio analisa uma das formas de organização social das relações de força que são legal e administrativamente definidas como crime comum violento, tal como elas se configuram contemporaneamente nas grandes cidades brasileiras, com particular referência ao caso do Rio de Janeiro. ${ }^{1}$ Tomo este complexo de práticas como uma das expressões atuais do desenvolvimento histórico do individualismo, ou seja, uma de suas formas cristalizadas, e o focalizo em seu impacto sobre a estruturação das rotinas cotidianas.

Esta questão poderia ser discutida em seus aspectos mais amplos e mais profundos, remetendo a quadros de referência abstratos e culturalmente inconscientes, responsáveis últimos pelos significados culturais que subjazem à formação do sentido e à orientação da ação por "criaturas" deste ordenamento. O produto deste modo de reflexão seria uma metanarrativa voltada para a compreensão global do processo social que, ao menos idealmente, daria conta de explicar tanto as particularidades do comportamento dos criminosos ao longo do tempo e do espaço, quanto as próprias interpretações sociológicas "de alcance médio" a respeito delas.

Alerto o leitor para o fato de que meu interesse é outro. Sem recusar sua relevância para as questões que elaboro, quero evitar esta abordagem que me parece conduzir a um modo de análise "desencarnado", que não é compensado pelas vantagens cognitivas que pode oferecer. A alternativa que proponho implica considerar a relação entre a produção simbólica e certas práticas sociais - isto que pressuponho uma expressão particular, tópica, específica, do individualismo contemporâneo - em sua concretude e singularidade mais imediata. Dar prosseguimento a este interesse requer definir um foco e um recorte que são estritamente analíticos. Comparada à alternativa anterior, esta também tem um alto custo: o abandono voluntário da possibilidade de produzir um argumento totalizador do tipo, por exemplo, da dialética do geral-particular-singular. Em outras palavras, para efeitos do presente texto, o crime comum violento não 
é o "momento" de um processo, mas sim um "objeto construído", parcial, autônomo e, portanto, auto-contido. ${ }^{2}$

Creio que, com esta decisão, mantenho-me colado ao que torna o crime comum violento um problema central da agenda pública e, em consequência, uma questão sociológica. Perco na abrangência da explicação, mas isso talvez seja compensado pela apreensão da profundidade da mudança nas relações sociais que o ganho em concretude proporciona. E aumento o volume de interlocutores potenciais, na medida em que posso participar diretamente de um debate crucial na atualidade, embora, como tentarei indicar adiante, meu argumento caminhe em direção muito distinta do ponto de vista mais difundido nesta discussão, em especial entre cientistas sociais, políticos e administradores.

Uma segunda observação introdutória que considero oportuna é consequência direta do modo de análise que escolhi. Segundo penso, ele implica necessariamente trabalhar no plano do modelo típicoideal, que é contrafactual por definição e não deve ser confundido com a descrição empírica da realidade. Adianto que não creio haver contradição entre esta afirmativa e a menção anterior à vantagem de ganhar em concretude: basta acrescentar a) que estarei lidando com um modelo típico-ideal "histórico", e não "sociológico", para usar a clássica distinção de Weber; e, b) que o recorte que proponho privilegia as regularidades dos cursos de ação cotidianos, mais que sua institucionalização formal.

Finalmente, uma última observação antes de iniciar o desenvolvimento do argumento. Visando compreender como as relações de força que estruturam, na atualidade, um complexo de práticas associadas ao que é definido como crime comum violento, interferindo radicalmente sobre a organização da vida cotidiana nas grandes cidades brasileiras, estarei esboçando a noção, que reconheço ainda muito incipiente, de "sociabilidade violenta". A intenção central é captar a natureza e o sentido do que me parece ser uma radical transformação de qualidade das relações sociais a partir das práticas de criminosos comuns, mudança que a crescente produção 
sociológica, ${ }^{3}$ excessivamente absorvida pelo debate sobre políticas de segurança e administração da justiça, tem tido enorme dificuldade de apreender. Isto significa dizer que meu argumento tem mais a ver com a perspectiva de análise do que com a apreensão empírica das características das práticas estudadas.

Assim, não é apenas devido às restrições de espaço de um artigo que tenho pouco a acrescentar ou discutir a respeito dos atributos descritivos do comportamento "real" dos atores, de modo que as escassas referências que faço são meramente ilustrativas. Sem dúvida, esta ausência acrescenta muita fragilidade ao raciocínio. No entanto, creio que ela não o inviabiliza, ao menos enquanto uma hipótese de trabalho plausível - que é o limite de minhas expectativas quanto a este texto - na medida em que a base de conhecimento "de fato" do complexo de práticas aqui discutidas é detalhada e amplamente compartilhada. É óbvio que tal conhecimento é pouco sistematizado e nada tem de homogêneo ou consensual, uma vez que combina, de um lado, as racionalizações da experiência vivida e sua crítica sociológica e, de outro, interesses e valores em conflito ou simplesmente distintos entre si e divergentes. Mas este é, como já indiquei, meu ponto de partida e meu tema: não pretendo "superar" esta complexidade nem tampouco "desencarnar" minha interpretação. ${ }^{4}$ Posto de forma um tanto brutal, creio que conhecemos muito, e cada vez mais, sobre as práticas da sociabilidade violenta, mas isto não nos tem levado a uma avaliação adequada sobre seu significado histórico e cultural.

Nestes comentários iniciais está implícito que não serão tratados como certos temas que também envolvem de alguma forma a ênfase na dimensão desestabilizadora da força envolvida nas relações sociais, constituem pontos críticos na rotina da vida cotidiana e, enquanto tais, também fazem parte dos problemas da agenda pública contemporânea. Isto porque sua construção cognitiva e seus significados culturais seguem caminhos diversos. Assim, cabe acrescentar que, adotando o recorte proposto, não estarei tratando de todas as formas de organização das relações sociais de força (mesmo considerando apenas a violência física; a "violência doméstica", por 
exemplo, não é aqui abordada), nem de todas as formas de crime comum (fica fora da análise o "crime de colarinho branco"), nem do conjunto da acumulação econômica da qual a "violência urbana" é um dos elos (a economia das drogas não é tratada), nem da organização social da violência em outras formações sociais (o "caso" colombiano, combinando narcotráfico e guerrilha, parece apontar para um desenvolvimento da violência privada com características muito distintas do Brasil).

Estou certo de que o leitor perdoará a repetição de algumas idéias que considero centrais para a compreensão de meu argumento, bem como a extensão do recurso às notas de rodapé, cujo objetivo é conservar a linearidade e a economia na apresentação do raciocínio.

\section{O crime comum violento e a "violência urbana" como representação}

Meu ponto de partida é uma constatação: existe uma expressão muito difundida e coletivamente aceita pelas populações urbanas para descrever cognitivamente e organizar o sentido subjetivo das práticas que envolvem o que legalmente se define como crime comum violento e suas vítimas atuais ou potenciais - violência urbana. Narrativas que visam explicar motivos da ação, assim como avaliações morais de condutas e fenômenos da vida cotidiana nas grandes cidades fundamentam-se nesta expressão para serem aceitas e compreendidas. Isto permite tomar a violência urbana como uma representação coletiva, categoria de senso comum constitutiva de uma "forma de vida". Neste sentido, ela não pode ser corrigida nem falsificada mas pode ser objeto de crítica racional. ${ }^{5}$

Analisada em seus conteúdos de sentido mais essenciais, a representação da violência urbana seleciona e indica um complexo de práticas que são consideradas ameaças a duas condições básicas do sentimento de segurança existencial que costuma acompanhar a vida cotidiana rotineira - integridade física e garantia patrimonial. Ela aponta para o crime comum, mas o foco de atenção é a força nele 
incrustada, a qual é definida como responsável pelo rompimento da "normalidade" das rotinas cotidianas, isto é, de seu caráter cognitiva e axiologicamente não-problemático e moralmente lícito. Esta é a razão pela qual violência urbana não é simples sinônimo de crime comum nem de violência em geral.

Trata-se, portanto, de uma construção simbólica que destaca e recorta aspectos das relações sociais que os agentes consideram relevantes, em função dos quais constróem o sentido e orientam suas ações. Desta perspectiva, possui um significado instrumental e cognitivo, na medida em que representa, de maneira percebida como objetivamente adequada a determinadas situações, regularidades de fato relacionadas aos interesses dos agentes nestes contextos. Mas, como toda representação, a violência urbana é mais do que uma simples descrição neutra. No mesmo movimento em que identifica relações de fato, aponta aos agentes modelos mais ou menos obrigatórios de conduta, contendo, portanto, uma dimensão práticonormativa institucionalizada que deve ser considerada. ${ }^{6}$

Conjugando estes dois aspectos, uma vez constituída como representação, a violência urbana é um "mapa" que apresenta aos atores um complexo de relações de fato e cursos de ação obrigatórios - expressão simbólica de uma ordem social, para todos os efeitos práticos. Mais explicitamente: a representação da violência urbana constrói um componente de obrigação normativa subjetivamente aceito que, em certas situações e sob determinadas condições, substitui cursos de ação relativos a outras referências sem, entretanto, cancelálas.

Antes de dar por apresentado este ponto de partida e passar a descrever esquematicamente como se estruturam as práticas representadas como violência urbana, alguns comentários adicionais são relevantes.

Em primeiro lugar, é pertinente propor, ao menos como hipótese de trabalho, que, como categoria de entendimento e referência para modelos de conduta, a violência urbana está no centro de uma formação discursiva que expressa uma forma de vida constituída pelo 
uso da força como princípio organizador das relações sociais. Ou seja, a representação da violência urbana capta, simbolicamente, um âmbito da vida cotidiana em que ocorre a universalização da força como fundamento de um complexo orgânico de práticas que suspende - sem, entretanto, cancelá-la ou substituí-la integralmente - a tendência à monopolização da violência pelo Estado, generalizando e "desconcentrando" seu uso legitimado. Assim, esta representação pode ser considerada a chave para a compreensão sociológica de um complexo de práticas sociais que não são coerentes com as rotinas cotidianas estatalmente organizadas, mas que, tampouco, podem ou devem ser evitadas ou negadas. Por outro lado, deve-se também notar que a violência urbana se constitui como uma compreensão "exterior" deste complexo de práticas, pois seu ponto de vista é o das rotinas convencionais (por isso produz-se como um problema na realidade da vida cotidiana e, por isso, tal problema tem os contornos específicos que procuro apresentar neste texto), mas ao mesmo tempo expressa adesão ao modo como elas se organizam. ${ }^{7}$ Como matéria inicial e desafio para a análise sociológica, sua riqueza está exatamente nesta ambigüidade: ela expõe a vivência coletiva do caráter fragmentado da forma de vida urbana no Brasil de hoje e introduz a possibilidade de apreender um padrão de sociabilidade construído (pelos dominados) como violência urbana,${ }^{8}$ a partir da incorporação crítica desta representação.

Como conseqüência desta observação, vale ressaltar um segundo ponto. As afirmativas acima, se corretas, reduzem a importância das freqüentes discussões sobre a magnitude real do incremento das práticas relativas à violência urbana, bem como sugerem a irrelevância de considerações sobre a "paranóia" da violência, apresentada como uma falha na percepção das populações urbanas, induzida pelo tratamento dado pela mídia ao crime violento. Do ponto de vista aqui adotado, estas são falsas questões, pois o que caracteriza a violência urbana, como qualquer construção simbólica, é justamente o fato de que ela constitui o que descreve. ${ }^{9} \mathrm{E}$, mais importante, a noção de violência urbana, como já foi dito, não se refere a comportamentos isolados, mas à sua articulação como uma 
ordem social (característica que permanece quer se venha a demonstrar ou não sua relação com o crescimento quantitativo do crime comum violento).

Finalmente, é necessário reconhecer que o raciocínio aqui desenvolvido é pouco freqüente. Mesmo não sendo objetivo deste ensaio empreender uma crítica das inúmeras interpretações atuais da violência urbana, pode ser útil à confrontação com o que me parece ser uma das bases desse relativo isolamento. Explícita ou implicitamente, muitos estudos sobre a violência urbana tomam-na como uma manifestação particular da violência "em geral", em alguns casos concebida como um atributo de qualquer relação social, em outros como historicamente contingente. A partir daí, segue-se uma análise da intensificação do fenômeno nos últimos anos, explicada segundo uma lógica fundada na hierarquização das formas de violência, às vezes causal - a violência de tipo X causa ou favorece $\mathrm{o}$ aparecimento da violência de tipo $\mathrm{Y}$-, às vezes histórica - a violência de tipo $\mathrm{X}$ é mais freqüente ou intensa em certas conjunturas do que em outras.

Da perspectiva aqui adotada, estas modalidades de interpretação incorrem em dois erros. Em primeiro lugar, deslocam a violência, de seu estatuto de objeto (na medida em que a análise sociológica deve incorporar a representação dos agentes), para o de conceito. Neste caso, ao mesmo tempo em que ela é o tema ou a questão a ser entendida, torna-se também o fundamento da análise. Como consequiência, em segundo lugar, a violência urbana é concebida em um espaço homogêneo (a violência "em geral"), ao longo do qual se hierarquizam vários subtipos.

Sem querer reduzir a riqueza das interpretações contemporâneas da violência a estes aspectos, fica portanto sugerido que há nelas uma certa circularidade (confusão entre objeto e conceito) e reducionismo (homogeneização) que precisam ser contornados. Uma das razões mais fortes que impõem esta necessidade é o fato de que a especificidade da violência urbana - que, afinal de contas, é o que interessa - se perde quando ela é concebida como um caso particular 
que só pode ser apreendido através do conhecimento da espécie a que pertence.

Retornemos às atribuições de sentido que caracterizam a violência urbana, as quais, como acaba de ser dito, privilegiam e destacam um âmbito das rotinas cotidianas caracterizado por um complexo de práticas reconhecidas como ameaças à integridade física e patrimonial e, em relação às quais se constroem modelos de comportamento e experiências vividas não convencionais. Tanto as justificativas subjetivas para a aceitação desses modelos quanto seu caráter imperativo, parecem ter escassa relação com motivos, garantias externas e demais condições situacionais relacionadas a outras esferas da vida social.

A capacidade de isolar e ordenar autonomamente este âmbito, que é intrínseca à representação da violência urbana, gera o sentido comum de uma vasta gama de práticas. Há muito tempo que assaltos, roubos, seqüestros, linchamentos, etc., vêm aceleradamente deixando de ser percebidos como desviantes e ocasionais - por agentes, vítimas e observadores - sem que, por isso, se possa afirmar que se trata tão somente de um processo de incorporação destas relações sociais à ordem institucional-legal, aos costumes dominantes ou às rotinas vividas como não problemáticas. Ao contrário, há fortes indícios de que os padrões convencionais de sociabilidade, regulados no âmbito do Estado, em determinados contextos e sob certas condições discutidas adiante - e a ênfase nestas condicionalidades é absolutamente central para uma boa compreensão do argumento aqui desenvolvido - perdem validade e são substituídos segundo disposições subjetivas e coerções reciprocamente articuladas, que constituem o âmbito próprio da violência urbana. É provavelmente devido a este destaque radical que as relações sociais construídas como "típicas" conservam a capacidade de mobilizar tão intensamente a atenção, os sentimentos e as emoções das populações das grandes cidades. E é também isto que permite afirmar que a violência urbana representa um complexo de práticas hierarquicamente articuladas ou seja, uma ordem social - e não apenas um conjunto inorgânico de 
comportamentos individuais, cujo sentido está fora deles, nos padrões de conduta que constituem a ordem social da qual tais comportamentos se desviam. Por outro lado, como venho insistindo, nada disto autoriza a afirmação de que a violência urbana destrói ou substitui os padrões convencionais de sociabilidade. A inovação histórica e o núcleo do problema teórico-metodológico é justamente a convivência, por contigüidade e não como "luta de valores", entre os dois padrões.

Finalmente, vale a pena repetir que as atribuições de sentido da violência urbana implicam, direta ou indiretamente, o reconhecimento pelas populações urbanas da fragmentação de suas rotinas cotidianas. Neste sentido, os modelos de conduta a que se refere esta representação procuram lidar com o medo e a percepção de risco pessoal e expressam, implicitamente, uma participação subordinada no complexo de práticas que constitui a violência urbana. Em outras palavras: as populações que produzem esta representação e por ela organizam (parte de) suas condutas não são as "portadoras" (os agentes produtores) do sentido desta ordem social. Construir a representação da violência urbana apenas lhes permite uma adesão orgânica que, em última instância, valida esta ordem social e ao mesmo tempo, reorganiza a vivência e permite a compreensão de uma rotina cotidiana fragmentada.

Antes de apresentar em breves traços a organização de uma sociabilidade violenta - núcleo do programa de trabalho que tento desenvolver neste artigo, de modo que aqui ela pode ser apenas esboçada -, considero útil uma reconstrução crítica do que creio ser a perspectiva dominante ${ }^{10}$ de sua interpretação, na medida em que ela torna inviável a compreensão do que proponho: que, nas grandes cidades brasileiras, está em adiantado processo de consolidação, no âmbito das rotinas cotidianas, uma ordem social cujo princípio de organização é o recurso universal à força. A recuperação deste que me parece ser o sentido mais fundamental da representação da violência urbana passa, portanto, pela recusa do ponto de vista adotado pelas análises mais difundidas. 


\section{Contra a interpretação dominante}

Nas últimas décadas, em virtude de uma dramática intensificação da experiência coletiva de insegurança pessoal, as populações urbanas vêm dando atenção especial aos problemas de manutenção da ordem pública nas cidades brasileiras, focalizando as dificuldades das agências de controle e repressão ao crime, mas envolvendo todo o processo institucionalizado de administração da justiça. De fato, parece estar cada vez mais distante o tratamento da questão como um simples "caso de polícia", estritamente ligado aos desvios de comportamento dos policiais, ou como um mero problema de eficiência dos aparelhos repressivos ${ }^{11}$. O tema enquadra-se como um dos aspectos do debate sobre a expansão da cidadania, com o foco ampliado de modo a incorporar de maneira mais direta a relação entre democratização e administração da justiça.

Entretanto, por todos os títulos relevantes, apesar de representar grande avanço no conhecimento sobre questões relacionadas à segurança das populações urbanas e à garantia de direitos civis, considero que o ponto de vista a partir do qual ele tem sido tratado, inviabiliza o entendimento das próprias práticas tidas como responsáveis pelos riscos que dão origem à preocupação coletiva com a questão. Isto porque, como tentarei sugerir em seguida, o ponto de vista a partir do qual o problema tem sido apreendido tem a peculiar característica de desmanchar o próprio objeto.

A primeira dificuldade diz respeito à compreensão do ator e da ação. A perspectiva dominante define os agentes que ameaçam a ordem pública pelas características jurídico-formais de suas atividades, como criminosos (ou seja, praticantes de certas categorias de ilícitos penais que constituem o crime comum violento). Em consequiência, as condutas em questão passam a ser compreendidas em termos das próprias regras violadas, e não em termos do sentido construído pelos criminosos para suas práticas. Nesta linha, a ineficácia dos aparelhos de manutenção da ordem, às vezes relacionada a problemas econômico-financeiros e de formação de pessoal, e sempre à impunidade e corrupção, é apresentada como a variável causal mais 
importante. Em outras palavras, a conduta criminosa é explicada pelo seu baixo "custo de oportunidade", em um tipo de interpretação no qual a formação dos comportamentos é vista como uma reação mecânica a condições contextuais, de modo que os criminosos seriam meros "aproveitadores" circunstanciais do estado de anomia provocado pela desorganização do sistema de administração da justiça. Supõe-se sem maiores questionamentos que os criminosos agem por referência às próprias regras infringidas, ou seja, pressupõe-se que os conteúdos de sentido que articulam motivos, orientações subjetivas e referências normativas são idênticos tanto para os criminosos quanto para o restante das populações urbanas.

Este esquema que, como já comentei, pode ser remetido à mais convencional teoria do desvio, se generalizou como a base de uma lógica explicativa que organiza um amplo debate público com argumentos bastante variados, porém todos convergindo, como acabo de sugerir, para referências a custos de oportunidade das condutas criminosas supostamente muito baixos. Além do fato de escorar-se em um pressuposto não demonstrado de que a formação da conduta é idêntica para criminosos e não criminosos, pode-se acrescentar uma outra dificuldade na sustentação empírica deste ponto de vista. Todas as pesquisas disponíveis demonstram que os riscos de toda ordem a que se expõem os criminosos são inequivocamente altíssimos, de modo que a insistência em baixos custos de oportunidade para explicar suas práticas sugere uma espécie de esquizofrenia analítica.

De qualquer forma, vale a pena neste momento adiantar outra dificuldade do esquema explicativo dominante, relacionada a suas implicações para o debate sobre propostas de intervenção política. À medida que o crime, e mais especificamente o crime violento organizado, aparece como resultado da ineficácia dos controles estatais em suas várias instâncias, favorecendo a adoção de comportamentos desviantes, segue-se como consequiência lógica o suposto de que tais condutas poderiam ser canceladas, inviabilizadas ou ao menos reduzidas a proporções toleráveis pela manipulação de variáveis institucionais. O funcionamento interno dos aparelhos estatais de controle social, portanto, fica reforçado como objeto 
privilegiado da atenção, o que contribui para manter em uma posição de mero epifenômeno as próprias práticas que deram origem a toda a reflexão.

De fato, uma vez que a construção de suas ações pelos próprios criminosos deixa de ser o objeto de atenção a ser considerado, o problema posto por suas práticas desaparece por uma espécie de efeito bumerangue, convertendo-se em uma questão de institution building que envolve a reorganização das agências da ordem estatal, suas relações com a sociedade civil e a formulação de políticas democráticas de segurança pública. Nesta linha, é certo que a compreensão das dificuldades de funcionamento das formas convencionais de regulação da vida cotidiana pode ser, e tem sido, ampliada. E também é certo que o debate em torno de políticas de segurança mais eficientes e democráticas que se articula a partir dela é extremamente relevante e vem dando bons frutos. No entanto, arrisco afirmar que se trata de um sucesso muito relativo, na medida em que, como acabo de sugerir, as práticas que, em última instância, estão na origem da reflexão ficam reduzidas a uma simples condição intersticial de desvio (cuja explicação é remetida ao baixo custo de oportunidade das condutas assim classificadas) e indicação de anomia (remetida à ineficácia regulatória do Estado).

A tentativa de criticar ou ultrapassar as representações de senso comum organizadas a partir da violência urbana, quebrando a unidade entre práticas e representações, tem como efeito a dissolução do objeto original, as práticas de agentes sociais definidos como criminosos. $\mathrm{O}$ problema do comportamento dos criminosos é substituído por uma reorientação do interesse analítico a partir da qual as deficiências do sistema de administração da justiça podem aparecer como um complexo causal, e as ações dos criminosos (a violência urbana) como conseqüências ou derivações - assim justificando, implicitamente, a ausência da análise específica da formação das condutas dos "portadores" da violência urbana.

Tem-se, como conseqüência, uma problemática desfocada, que gera uma série de distorções, das quais a mais importante é um certo 
etnocentrismo, indiretamente mencionado linhas acima: a suposição de que os conteúdos de sentido que organizam as ações de criminosos e não-criminosos são os mesmos, em ambos os casos expressões subjetivas dos contextos normativos regulados pelo Estado. ${ }^{12}$

No entanto, é preciso acrescentar que todas estas críticas, por muitas que sejam, não desqualificam a interpretação dominante, apenas negam que ela se constitua em uma explicação causal da violência urbana. De fato, ela corresponde a toda uma imensa e multifacetada discussão que tematiza a crise institucional e de legitimidade em que vivemos - e, neste sentido, parece-me irretocável.

Neste ponto, devo desviar-me por um instante da questão central do presente texto, para acrescentar um rápido comentário que explicite como, por que e em que termos posso aceitar a adequação da interpretação dominante apesar das críticas que venho apresentando.

Considero que atravessamos, nas últimas décadas, uma profunda crise de legitimidade que expõe com toda intensidade a fraqueza estrutural do Estado brasileiro. Especificamente, creio que estamos saindo do que poderia ser considerada uma versão cabocla dos "trinta anos gloriosos", capaz de reproduzir nossa secular desigualdade social e, ao mesmo tempo, favorecer a inclusão social e modernizar a configuração do Estado, absorvendo e pacificando os conflitos. Refiro-me a um tripé que começou a ser produzido por volta dos anos 30 do século XX, mas atingiu sua forma mais acabada durante as três décadas subseqüentes ao pós-guerra, o qual pode ser muito brevemente esquematizado como se segue: ${ }^{13}$

a) no plano da economia, um forte e sustentado crescimento baseado em um bem-sucedido processo de substituição de importações, favorecendo a mobilidade ascendente e a inclusão social;

b) no plano político-institucional, a "cidadania regulada" (Santos, 1979), que organizou a expansão econômica de maneira a não ameaçar a desigualdade fundamental da sociedade brasileira (por sua vez uma das condições do 
caminho adotado para o crescimento econômico) e reduziu, alongando no tempo, o processo de inclusão social, controlando as pretensões universalistas contidas nas lutas sociais do período na medida em que as absorvia;

c) no plano simbólico-cultural, a "ideologia do desenvolvimento", que articulava as justificativas para o caminho de crescimento econômico adotado e fazia as lutas sociais convergirem para a reprodução da "cidadania regulada", em duas dimensões conjugadas. Por um lado, os gargalos da expansão econômica eram atribuídos às relações internacionais (desequilíbrio nos termos de troca do comércio com os países centrais, "dependência", imperialismo, etc.), reorientando e reduzindo a virulência dos conflitos internos. Por outro, a ideologia do desenvolvimento favoreceu uma espécie de socialização antecipatória que garantia a univocidade das lutas sociais, na medida em que os "cidadãos de segunda classe" (ou simplesmente não-cidadãos) podiam perceber-se como futuros "cidadãos completos", seja pela via da mobilidade individual considerada como uma expectativa viável, seja pelo progressivo fortalecimento coletivo como categoria econômica, percebido como capaz, em futuro discernível, de forçar a porta de entrada na cidadania plena;

d) em condições “normais", este tripé garantia a transformação de conflitos de legitimidade - que questionariam a desigualdade básica da sociedade brasileira —, em conflitos distributivos capazes de serem absorvidos na estrutura institucional como parte rotineira da luta política. No entanto, volta e meia esta pacificação era posta em dúvida, fazendo aparecer a fragilidade básica do Estado brasileiro, que sempre perseguiu uma legitimidade que só obtinha parcialmente. Mas a crise era resolvida através do mecanismo da cidadania regulada, pela incorporação das categorias sociais mais ameaçadoras - e todo o arranjo (obviamente não intencional) acima esboçado se reproduzia por mais algum tempo. 
Este modo de integração social começa a desabar em meados dos anos 1970. A crise do petróleo se superpõe ao esgotamento do processo de substituição de importações que já começava a se manifestar, inviabilizando a reprodução do sistema de dominação que se consolidara nas décadas anteriores. Além disto, expõe a fragilidade básica de um Estado nacional que não foi capaz de reduzir significativamente as desigualdades sociais, tendo apenas conseguido contornar a radicalidade das lutas sociais da maneira acima esquematizada. Explicita-se, assim, em toda a sua crueza, uma crise de legitimidade durante muito tempo abafada, a qual se manifesta, entre outros aspectos, pela incapacidade do conjunto das instituições estatais de garantir padrões de sociabilidade inclusivos e coletivamente aceitáveis.

Considero que o que venho chamando de interpretação dominante da criminalidade violenta representa uma das inúmeras tematizações da dupla face desta crise: institucional e de legitimidade. Sua atenção concentra-se na capacidade de controle social por parte do Estado e a análise orienta-se para a busca de formas de reforçá-la, ultrapassando o arranjo anterior, de modo a combinar eficiência com controle da sociedade e, assim, garantir a adesão ativa da população.

Neste sentido, o que venho chamando de ponto de vista dominante constrói uma problemática "real", além de ética e politicamente relevante. Pondo em tela de juízo certas "garantias externas" da legitimidade do Estado - isto é, a eficácia das agências de segurança pública e seu teor mais ou menos democrático - aponta, em última instância, para a profunda crise de autoridade amplamente reconhecida e, por isso mesmo, questão central da agenda pública.

Entretanto, a fim de explicar o sentimento de insegurança generalizada que está no centro da experiência de vida urbana na atualidade, esta perspectiva estabelece uma seqüência de nexos causais entre:

a) uma crise de legitimidade do Estado;

b) o enfraquecimento da capacidade de controle social por parte das agências estatais, em particular 
c) o esgarçamento da ordem pública, devido ao mau funcionamento de suas "garantias externas";

d) a ampliação do recurso à violência como meio de obtenção de interesses; e,

e) a expansão e organização da criminalidade que recorre a este meio.

Trata-se, portanto, da imputação de uma cadeia causal que explica a desconcentração da violência física (o uso generalizado de violência pelos criminosos indica que o Estado perde seu monopólio de fato, embora mantenha-o formalmente) por processos estritamente internos à própria ordem estatal, considerada como padrão universal de sociabilidade. Nesta lógica, aquilo que era inicialmente objeto da atenção, posto pela vivência da insegurança cotidiana - as práticas ameaçadoras de agentes definidos como criminosos comuns violentos - agora reaparece como resultado ou conseqüência mecânica de relações sociais "desencaixadas" (Giddens) das próprias condutas criminais e apresentadas como explicação destas. O momento de "reencaixe" pelos criminosos do sistema político-institucional aparece como simples correia de transmissão daquelas relações, já que é visto como gerando uma simples conduta desviante, expressão da ausência de uma sólida sustentação dos parâmetros normativos nas áreas urbanas. Fundamentado neste esquema explicativo, desenvolve-se, como é mais do que sabido, um amplo debate sobre propostas de intervenção corretiva, todas girando em torno da atividade regulatória e das políticas substantivas do Estado. ${ }^{14}$

Para tornar menos abstratos estes comentários, olhemos mais de perto a explicação dominante. Ela toma como unidade de análise a relação entre dois agentes: de um lado os próprios criminosos e, de outro, os policiais enquanto encarregados diretos da atividade institucional de manutenção da ordem pública em sua operação mais imediatamente incrustada nas rotinas cotidianas. Entretanto, não parece exagero sugerir que praticamente todo o peso da lógica explicativa que tenta apreender esta relação recai sobre as condições e o modo de funcionamento do aparelho repressivo. Começando com 
a atuação dos policiais, mas raramente restringindo- se a eles, a explicação enfatiza a crise moral e de autoridade das instituições responsáveis pelo controle social e administração da justiça, causa de uma incapacidade radical de cumprimento de suas atribuições, a qual se manifesta sob as mais variadas formas de corrupção dos agentes da ordem, impunidade dos criminosos, e tratamento discriminatório das populações mais pobres. O resultado final é a criminalização da própria polícia, o aprofundamento da desproteção das camadas populares (agravamento do problema de garantia de seus direitos civis) e o estímulo ao desenvolvimento do crime organizado.

De passagem, note-se que este é o nível mais imediato e tópico de uma explicação cujo sentido profundo é extraído do reconhecimento de que ela trata da expressão localizada de uma crise institucional que é antes política que econômica (o que vejo como uma vantagem do ponto de vista dominante sobre as explicações economicistas, que não desapareceram, mas são cada vez menos difundidas). De fato, embora seja recorrente a menção à penúria das agências governamentais, em uma linha de raciocínio cada vez mais generalizadora que a remete à crise fiscal e à reconversão da economia, estas causas de natureza econômico-financeira têm antes o estatuto de variáveis intervenientes na interpretação dominante, pois a ineficiência e a desmoralização interna do aparelho policial são vistas como parte de uma crise política que afeta o conjunto da relação entre Estado e sociedade.

Esta descrição, obviamente muito esquemática e superficial, não pretende captar a riqueza e variedade das análises, mas apenas expor o ponto de vista que fundamenta a lógica explicativa da insegurança da vida cotidiana nas grandes cidades brasileiras. A intenção foi apenas descrever o que considero como o nexo causal básico da interpretação, construída como uma relação entre ordem pública e criminalidade violenta na atualidade: de um lado, como variável independente, uma profunda crise de autoridade que gera impunidade e corrupção e torna ineficaz o funcionamento das agências estatais, inclusive e especialmente as relacionadas ao controle social e à administração da justiça; de outro, a variável dependente a ser 
explicada: o crescimento do crime violento organizado nos espaços em que a atividade regulatória e as políticas substantivas do Estado não conseguem preencher.

Creio que posso, agora, resumir os principais elementos de minha crítica ao que considero ser o ponto de vista dominante no debate em torno da criminalidade violenta contemporânea, sem levar o leitor a pensar que pretendo desqualificá-lo integralmente:

a) o agente é definido em termos do estatuto legal de seu comportamento, e não da análise de suas práticas concretas, a qual levaria à discussão das características específicas da formação da conduta dos "portadores" da violência urbana;

b) o objetivo implícito é, portanto, romper com as representações de senso comum da violência urbana;

c) o esquema interpretativo fundamenta-se na suposição de que o comportamento de qualquer agente individual pode ser compreendido como uma reação adaptativa a contextos normativos definidos. Neste aspecto não há diferença entre criminosos e não-criminosos;

d) este esquema articula uma análise objetivada e exteriorizada das práticas que geraram todo o esforço de entendimento em virtude de seu caráter vivido como problemático por ameaçarem as rotinas cotidianas organizadas em torno da ordem normativa garantida pelo Estado;

e) desta forma, desloca-se o foco das práticas para o aparato político-institucional responsável pelo controle normativo;

f) a associação entre os aspectos "b" e "d" sustenta uma concepção totalizadora da vida social que se expressa concretamente na suposição da universalidade da ordem estatal (o que não implica pressupostos de consenso nem de integração social monolítica, pois é justamente a falta de um grau aceitável de ambos que se torna objeto da atenção); 
g) por tudo isso, condições contextuais de possibilidade de desenvolvimento de certos cursos de ação (as práticas que o senso comum define como violência urbana) transformamse em causas destas condutas, de modo que a formação das ações que deram origem a toda a reflexão desaparece das considerações. ${ }^{15}$

Na próxima seção procuro sugerir que um ponto de vista que recupere a análise das práticas sociais propriamente ditas e que não pretenda negar ou ultrapassar a violência urbana pode revelar e pôr em discussão, como hipótese de trabalho, uma tendência que a explicação dominante não tem condições de perceber: a transformação da violência, de meio de obtenção de interesses minimizado pela sua concentração como monopólio formal do Estado, no centro de um padrão de sociabilidade em formação que não se confronta com a ordem estatal, mas lhe é contíguo. Creio que é justamente isso que confere especificidade histórica à violência contemporânea nas grandes cidades - sua capacidade de fragmentar, no sentido forte deste termo, a vida cotidiana - tornando-a um objeto sociológico singular e um problema social muito mais complexo e profundo do que sua apreensão pelo que considero ser a interpretação dominante faz crer.

\section{Traços da morfologia da sociabilidade violenta}

Fundamentado nas considerações desenvolvidas nas seções anteriores, gostaria de apresentar um esboço de interpretação alternativa que, como acabo de sugerir, não pretende negar a relação entre baixa legitimidade, dificuldade de controle social (isto é, de validade da ordem legítima) e possibilidade de desconcentração da violência, desenvolvendo a noção, ainda muito incipiente, de "sociabilidade violenta".

Creio ser possível começar lembrando que a característica central da representação da violência urbana é captar e expressar 
uma ordem social, mais do que um conjunto de comportamentos isolados. Ou seja, as ameaças percebidas à integridade física e patrimonial não provêm simplesmente de agentes e comportamentos isolados, mas de um complexo orgânico de práticas. Esta construção gera disposições de conduta que levam em consideração os códigos organizadores deste complexo. Mas não parece despropositado agregar que a violência urbana, como referência para a formação das ações, está longe de cancelar ou substituir orientações subjetivas relacionadas à ordem estatal. Até porque é a partir destas que a representação da violência urbana se constrói, pois a experiência que a fundamenta é a ameaça à segurança, e a avaliação desta se reporta a uma ordem institucional-legal ideal tomada como parâmetro. Daí minha sugestão anterior, de que a violência urbana é uma categoria produzida pelos dominados, caracterizando uma apreensão "exterior" desta ordem social, mas nem por isto menos coerente com ela.

Assim, a violência urbana apreende uma novidade em gestação nas últimas décadas. Seu ponto de partida é o reconhecimento de que os comportamentos violentos - de agentes individuais ou bandos que se formam e desmancham aleatoriamente, sem permanência no tempo - não desaparecem, porém já não gravitam mais em torno da ordem estatal, destacando-se e organizando-se como uma ordem instituída. Entretanto, se estou certo quanto à convivência entre dois conjuntos distintos (mas não necessariamente opostos) de orientações da ação, este deve ser apenas o ponto de partida da reflexão. De fato, o desafio teórico e político é explorar como é possível esta relação de mera contigüidade, uma vez que ela nega a unidade fundamental da vida social representada, no quadro conceptual geral que estou adotando, pela idéia de "luta (inconsciente) de valores" que se processa na subjetividade dos agentes durante a formação de suas condutas, ao perseguirem fins objetivamente contraditórios. Para tornar o ponto ainda mais claro, repito que, se minha descrição da violência urbana é correta, não há luta, mas convivência de referências, conscientes ou pelo menos claramente "monitoradas", a códigos normativos distintos e igualmente legitimados, que implicam a adoção de cursos de ação divergentes. 
Não tenho a pretensão de resolver o problema, mas uma hipótese para estudos posteriores pode começar repetindo a indicação da configuração básica do complexo de práticas apreendido pela representação da violência urbana: a transformação do uso da força, de meio eventual de obtenção de interesses, em princípio de regulação das relações sociais. ${ }^{16}$ Mas este padrão de articulação das práticas sociais autonomiza um âmbito das rotinas cotidianas, produzindo uma "forma de vida" que não se "desencaixa" e, portanto, não interfere sobre os cursos de ação articulados em torno da ordem estatal. $\mathrm{Na}$ medida em que o princípio que estrutura as relações sociais é a força, não há espaço para a distinção entre as esferas da política, da economia e da moral. Da mesma maneira, pode-se caracterizar os agentes responsáveis pela gênese e consolidação deste ordenamento como uma espécie de caso-limite do desenvolvimento do individualismo, em que o abandono de referências coletivas moderadoras da busca dos interesses individuais acaba por eliminar também o autocontrole (mas não o raciocínio instrumental que garante a forma social de "fins" ou "interesses" a puros "desejos" irrestritos ou "pulsões"). ${ }^{17}$ Para os portadores da violência urbana, o mundo constitui-se em uma coleção de objetos (aí incluídos todos os demais seres humanos, sem distinguir seus "pares") que devem ser organizados de modo a servir a seus desejos. Há, certamente, limites para a realização de tais desejos, mas eles têm o estatuto da resistência material representada pela objetividade do mundo (inclusive os limites impostos pelo reconhecimento da força dos demais portadores).

Se estas considerações estão corretas, haveria uma disjunção na formação das condutas entre os portadores da violência urbana (os quais, como acabo de sugerir, não podem ser vistos como um coletivo organizado em torno de interesses ou valores comuns que, em última instância simplesmente, não existem) e os contingentes dominados, capazes de, sob certas circunstâncias, aderir a esta ordem sem cancelar a aceitação da ordem estatal.

Uma ordem social como esta não pode ser simplesmente entendida como uma configuração empiricamente dada mas, por outro lado, as noções de reciprocidade, solidariedade, intersubjetividade, etc., tão caras à tradição do pensamento social, têm uma utilidade limitada para sua análise, uma vez que a ação se constitui como um 
conjunto de comportamentos monocordicamente organizados sob a forma de tentativas de controle de um ambiente que só oferece resistência física à manipulação do agente. O que "une" estas condutas em um complexo de práticas organizadas é justamente o reconhecimento (estritamente instrumental) da resistência física representada pela força de que podem dispor os demais agentes.

Em outras palavras, a formação das práticas típicas da violência urbana não passa por justificativas de valor, a não ser as que os dominados desenvolvem como parte da representação da violência urbana. Mas esta é uma compreensão "exteriorizada", dos dominados, que expressa seu reconhecimento da fragmentação da vida cotidiana, relacionando-se apenas com desejos, pulsões e/ou interesses estritamente individuais regulados pura e simplesmente pelo reconhecimento de uma hierarquia de força física (com maior ou menor recurso a tecnologias que a tornam mais eficiente) produzido pela reiteração de demonstrações factuais e não por acordo, negociação, contrato ou outra referência comum compartilhada. ${ }^{18}$

Se esta linha de reflexão tiver alguma plausibilidade, podemse extrair algumas implicações que talvez sejam úteis para orientar estudos posteriores.

A primeira delas diz respeito ao fato de que a "sociabilidade violenta" não dispõe de uma linguagem própria, recorrendo, para expressar-se como "forma de vida", a uma profunda resignificação da linguagem corrente. Não me atrevo a elaborar esta questão, que demanda muito mais pesquisa e conhecimento empírico do que possuo. Chamo apenas a atenção para o fato de que eventuais erros de "tradução", ao desconsiderarem este ponto, podem acarretar - na realidade, creio que têm acarretado -, por parte dos analistas, o puro e simples desconhecimento da peculiaridade da "sociabilidade violenta" que tentei elaborar acima. Talvez uma releitura da linguagem da "sociabilidade violenta" devesse começar considerando que, se é possível pensá-la, com Weber, como "empresa", dever-se-ia ao mesmo tempo considerar que não faz sentido aplicar este conceito continuando a aceitar a separação entre "esferas de valor", isto é, distinguindo entre política e economia. 
Uma segunda implicação que gostaria de mencionar dirige-se para a problematização do que pode ser entendido como "organização da criminalidade", uma questão que vem sendo muito debatida e estudada, e que está implicitamente tematizada no presente trabalho, embora, com certeza, meus comentários sobre a violência urbana como ordem social pouco tenham a ver diretamente com a formação de grupos de criminosos e não apenas os envolvidos com o tráfico de drogas. ${ }^{19}$ Mas os modelos correntes de entendimento da organização da violência criminal ("banditismo pré-moderno", "gangue juvenil", "máfia", etc. e, no limite, "exército") simplesmente não se aplicam. Isto porque todos eles se baseiam em princípios como honra, lealdade, companheirismo, cooperação, solidariedade, que reproduzem a idéia tradicional de uma pacificação entre os iguais (redução do recurso à violência aberta entre os pares), reorientando as práticas violentas para o "exterior". Desta forma, mantém-se também inalterada a compreensão do uso da força como meio de obtenção de interesses e não como princípio de organização das práticas.

Mas negar a adequação destes modelos não implica o desconhecimento da existência, não propriamente de "ação coletiva", se considerarmos o sentido corrente desta expressão, que sempre contém, de alguma forma, a idéia de cooperação em torno de objetivos comuns, mas, digamos, de "práticas individuais conjugadas". Estas ações, embora possam gerar acumulação (ou articular-se com empreendimentos que visam lucro e/ou poder, quase sempre eles também ilegais que operam nos limites exteriores da ordem estatal) não são propriamente empresas, no sentido de uma hierarquia orientada para fins coletivos. O complexo formado por estas práticas também se fundamenta no mesmo princípio geral de subjugação pela força, constituindo-se em uma espécie de amálgama de interesses estritamente individuais, com um sistema hierárquico e códigos de conduta que podem ser sintetizados pela metáfora da "paz armada": todos obedecem porque e enquanto sabem, pela demonstração de fato em momentos anteriores, serem mais fracos, com a insubmissão 
implicando necessariamente retaliação física. No limite, pode-se dizer que não há "fins coletivos" nem "subordinação"; todas as formas de interação constituem-se em técnicas de submissão que eliminam a vontade e as orientações subjetivas dos demais participantes como elemento significativo da situação.

Se é correto afirmar, como proponho, que na ordem da violência urbana as práticas se articulam através de demonstrações factuais de força e não por intermédio de referências de valor compartilhadas, a aplicação desses modelos de organização da violência criminal apenas expressam uma postura etnocêntrica que não reconhece a especificidade da configuração que analisam. De fato, minha hipótese é que não se trata de "contra-poderes" ou de formas localizadas de "capitalismo aventureiro" (pois este último só faz sentido quando relacionado ao "sóbrio capitalismo burguês" e ambos só fazem sentido a partir da diferenciação entre esferas de valor que, como venho sugerindo, desaparece na sociabilidade violenta).

Finalmente, uma palavra sobre a distribuição territorial da coexistência entre ordem estatal e violência urbana. Nenhum aspecto do argumento aqui desenvolvido implica suposições sobre uma eventual homogeneidade geográfica ou ecológica desta combinação. De fato, parece ser inquestionável que, ao contrário, há grande heterogeneidade, tanto em razão de práticas intencionais de autoisolamento dos estratos mais favorecidos quanto de processos mais impessoais que explicam o peso relativo de cada uma das ordens nas áreas das grandes cidades, ${ }^{20}$ sem esquecer as considerações logísticas, instrumentais, dos portadores da sociabilidade violenta.

Assim é que, embora a violência urbana seja uma característica geral da configuração social das cidades brasileiras que abrange, portanto, todo o seu território, é mais ou menos consensual que ela afeta mais direta e profundamente as áreas desfavorecidas, especialmente as favelas, provavelmente devido à forma urbana típica desses locais, em geral muito densos e com traçado viário precário, 
dificultando o acesso de quem não está familiarizado com eles e, portanto, favorecendo o controle pelos agentes que lograrem estabelecer-se neles. Os moradores destas áreas estão, mais diretamente submetidos à violência urbana e, portanto, merecem um comentário especial.

Como toda a população urbana, eles articulam suas práticas segundo uma dupla inserção, como participantes da ordem estatal e, paralelamente, da sociabilidade violenta. Quanto à primeira, eles têm se organizado em torno de variados projetos, individuais e coletivos, com diferentes graus de adesão. Pode-se dizer, assim, que estão ativamente engajados no entendimento de sua própria situação, independente da direção das práticas que este entendimento indica (as quais, como sabemos, variam muito no tempo e no espaço). Neste sentido, mesmo nos momentos mais autoritários de funcionamento do controle estatal sobre a organização de suas condutas, tem havido espaço para o desenvolvimento de uma capacidade autônoma de formas de ação visando à obtenção de seus interesses. Mas quanto à adesão à sociabilidade violenta, ela se caracteriza antes como submissão que como subordinação, na medida em que este último termo implique a existência, em algum grau, da formação de condutas autônomas. Enraizada como um âmbito da vida cotidiana, ela não produz um distanciamento entre as fontes institucionalizadas de poder e as rotinas cotidianas, reduzindo a limites mínimos a comunicação necessária à produção do entendimento da própria situação, que é a base da formação autônoma da conduta.

A sociabilidade violenta, levando nestes locais o risco pessoal ao paroxismo, gera medo nos agentes sociais que continuam a se constituir de forma tal que não estão preparados para "abandonar-se" à violência como princípio (é por isto que eles constituem o estrato dominado). A conhecida "lei do silêncio" parece ser mais perniciosa do que normalmente se imagina: não se trata apenas do fechamento para os "de fora" das populações mais diretamente afetadas pela sociabilidade violenta, mas da incomunicabilidade entre seus próprios membros produzida pelo medo e pela desconfiança. Esta talvez seja a conseqüência mais perversa da implantação da sociabilidade 
violenta como ordem instituída. As populações que ela submete continuam, de certa maneira, a viver sua vida "normal", organizadas como subalternas que são à ordem estatal, mas sob a condição de serem impedidas de se apropriarem coletivamente da "outra parte" desta mesma normalidade cindida.

\section{Conclusão}

Este texto apresenta um programa de trabalho e, como tal, não comporta uma conclusão. Entretanto, mesmo correndo o risco de reforçar o caráter anticlimático deste final, eu gostaria de retomar um comentário anterior, de que a interpretação dominante articula uma reflexão a partir da qual uma intervenção social de caráter "corretivo", que recomponha a legitimidade do Estado, reforçando assim a eficácia dos controles representados pelo sistema de administração da justiça, teria como resultado a recomposição da integração social nas grandes cidades brasileiras. De fato, boa parte da discussão pública na atualidade diz respeito à natureza, ao sentido e aos protagonistas das intervenções mais adequadas para este fim. Como sugeri ao longo deste trabalho, o elemento comum que estrutura este debate é acreditar que medidas político-institucionais, reorganizando o quadro normativo em que se desenvolvem os conflitos e as práticas, são suficientes para recompor o tecido social.

Boa parte deste artigo volta-se para justificar uma rejeição deste ponto de vista e sugerir um programa de investigação voltado para a compreensão do desenvolvimento de uma forma radicalmente nova (mas, como deve ter ficado claro, nada revolucionária) de organização social que, longe de representar simples expressão da ineficácia dos controles estatais, tem um desenvolvimento relativamente independente destes. Acho muito prematura mesmo uma simples tentativa de lidar com propostas de manipulação da sociabilidade violenta, seja para cerceá-la, seja para reorientá-la. Mas talvez seja possível começar pela idéia de que, qualquer que venha a ser o caminho, ele terá que se orientar para medidas capilares, no plano das práticas cotidianas, que estimulem o reconhecimento mútuo, de modo a reconstituir a alteridade cancelada pela forma de vida representada pela violência urbana. 


\section{Notas}

1 O foco no Rio de Janeiro justifica-se pelo singelo motivo de que esta é a cidade onde moro e que conheço melhor, tanto pela experiência existencial direta quanto pelo trabalho sociológico. Entretanto, além disso, creio que o Rio pode ser tomado como um "caso particular do possível", "bom para pensar" a sociabilidade violenta.

2 Apresentando de uma terceira maneira o estatuto do meu argumento, eu diria que não estou interessado em falar sobre a "verdade" das relações de força de que trato, mas em propor uma interpretação, entre outras possíveis, sobre como os envolvidos as vivem - como as praticam, experimentam e representam.

3 Dentre os inúmeros balanços críticos contendo uma revisão da bibliografia brasileira, cf. Lima et al. (2000) e Adorno (1993). Cf., ademais, o pioneiro trabalho de Zaluar (1985) e, para uma interpretação mais recente, Peralva (2000).

4 Ironicamente, até onde estou informado, é uma obra de ficção de Paulo Lins que contém o equivalente a uma "descrição densa" (Geertz) do crime comum violento mais compatível com a perspectiva aqui proposta (Lins, 1997). O presente texto estava em final de redação, inclusive com esta citação já incluída, quando o filme que levou o livro de Paulo Lins à tela se transformou em sucesso de bilheteria e crítica, gerando enorme polêmica sobre a postura moral adotada por produtores e diretores. Em uma palavra, à parte a denúncia de procedimentos pouco ortodoxos na realização das filmagens, seus críticos identificam o que seria uma incompatibilidade entre o tratamento estético e uma postura moral dos criadores diante dos aspectos factuais do enredo. Creio que seria possível sugerir que, sob a roupagem de um debate ético-político, esta discussão expressa a dificuldade da percepção social convencional (leiga e/ou sociológica) em reconhecer a mudança de qualidade do crime violento mas, ao mesmo tempo, o fascínio com aquilo que está fora de sua capacidade de apreensão. No centro da polêmica está a produção de uma antinomia que a perspectiva dominante não consegue dissolver: de um lado, o modo de tratamento estético de práticas criminosas, considerado por alguns como uma glamourização moralmente indefensável; de outro, o reconhecimento da imensa riqueza factual de uma descrição "interna" desses fenômenos que demonstra sua distância das relações sociais mais convencionais, expondolhes o caráter radicalmente singular, que não é questionado em sua facticidade, mas apenas em seu significado moral - interditando, em consequência, sua apreensão cognitiva. Em suma, creio que o problema construído pelo debate suscitado pela recepção do filme não diz respeito à especificidade do crime violento - que é o elemento comum, que unifica os pólos da discussão - mas antes ao seu estatuto, ou seja, se ela deve ser publicamente exposta e discutida e, em caso afirmativo, qual a tematização ética e/ou esteticamente legítima e politicamente oportuna. 
5 “A 'incorrigibilidade' do senso comum como recurso necessário para a análise social não deveria esconder seu status de tópico (...) Se o senso comum é em si organizado como um 'tópico', as crenças que estão envolvidas (...) estão, em princípio, abertas à avaliação racional" (Giddens, 1997, p. 296). Considero que, adotando esta perspectiva, não preciso tratar a violência urbana nem como falsa consciência, nem como dado bruto da realidade, nem como categoria mental abstrata e arbitrária, passível de ser sociologicamente desmontada em suas regras de construção. Fico também desobrigado de desenvolver uma discussão conceptual sobre a violência "em geral".

6 No que diz respeito à compreensão da violência urbana, a conexão entre os modelos de conduta e a perda de valores éticos tem galvanizado a atenção da observação sociológica (denunciando seu compromisso essencial com uma perspectiva jurídico-institucional de análise), geralmente em uma perspectiva de denúncia tão apaixonada que algumas vezes chega a impedir, outras distorce, a própria percepção de que, junto com garantias exteriores de imposição, estes modelos são aceitos como obrigatórios. Se a aceitação de tais máximas de conduta e a legitimação da autoridade a elas relacionada se associa ou não a uma ética mundana questão colocada pelo que parece ser uma absoluta falta de transcendência nos conteúdos normativos dos modelos de conduta da sociabilidade violenta (que nem por isto pode ser considerada uma simples ordem empírica) - é outro problema.

7 As reiteradas afirmativas a respeito da "banalização" da violência, sustentando-se no que consideram um aumento quantitativo do crime comum violento, parecem reconhecer a dimensão de adesão, mas não o caráter problemático captado pela violência urbana.

8 É tentadora a possibilidade de relacionar estes comentários à noção fenomenológica de "mundos paralelos", mas não resta dúvida de que ela só caberia como metáfora.

9 Estes comentários não desqualificam as análises que apontam o efeito ideológico - estigmatização e reforço do preconceito - contido no uso, intencional ou não, da representação da violência urbana como reforço do "mito das classes perigosas". O que eles desqualificam é o recurso a estas interpretações como forma de recusar o caráter "real" - sua concretude como experiência vivida - da ordem social captada por ela.

10 Talvez fosse melhor substituir a expressão "perspectiva dominante" por "perspectiva erudita", para sublinhar o fato de que se trata de um entendimento muito generalizado entre cientistas sociais, políticos e administradores mas nem tanto entre os segmentos subalternos, ou pelo menos não em toda a sua coerência. O leitor já terá percebido que uma de minhas hipóteses é que há pouca consistência entre a "perspectiva dominante" (erudita) e a violência urbana enquanto matriz de 
representações orgânicas vinculadas a um complexo de práticas essencialmente semelhantes. Na próxima seção, procuro apresentar uma explicação para a disjunção entre elas. No entanto, devo reconhecer que, infelizmente, não disponho de elementos - evidências e aparato conceptual - para um tratamento sistemático desta questão, em particular porque, como o leitor também terá percebido, não creio que sejam aplicáveis, sem uma revisão muito profunda que não estou preparado para empreender, os quadros de referência construídos a partir das várias acepções da idéia de "luta simbólica".

11 Esta afirmativa, é claro, não nega que o evidente descalabro administrativo, político, econômico, etc. - dessas agências responde em boa parte pela visibilidade e permanência do tema na agenda pública, bem como para a própria hegemonia do enquadramento cognitivo que descrevo em seguida. (No Brasil, ainda no final da década de 1970, desde as pioneiras contribuições de Edmundo Campos Coelho (1978 e 1987, por exemplo), vem se acumulando um volume crescente de pesquisas sobre a atuação da polícia na repressão ao crime comum, em especial a Polícia Militar, e sobre a vida nas penitenciárias. Entretanto, dadas as dimensões e o foco do presente artigo, esta literatura não pode ser aqui incorporada).

12 É evidente que fica no ar a questão de porque, dado que os controles estatais não funcionam bem, tornando a violência urbana "racional" para os atores individuais devido ao baixo custo de oportunidade, só uma pequena parte da população pratica o crime violento. É neste quadro, como forma talvez inconsciente de resolver esta dificuldade, que se desenvolvem as interpretações economicistas que, de diferentes maneiras, associam pobreza e crime. A propósito, cf. a brilhante crítica de Coelho (1978).

13 Ainda de forma esquemática, porém, um pouco mais desenvolvida do que é possível no espaço deste artigo, comento esta questão, focalizando as características mais permanentes do desenvolvimento do capitalismo em "A (des)organização do trabalho no Brasil urbano" (Silva, 1990). Ali, também sugiro que a constituição do assalariamento em nosso país foi incompleta e a incorporação à cidadania foi seletiva.

14 Deixando de lado as diatribes moralistas, muito comuns mas aparentemente inócuas, destaco, dentre a miríade de possíveis ilustrações desta lógica explicativa, matéria publicada na revista Veja de 08/09/93, a propósito do episódio conhecido como a "chacina de Vigário Geral", que me parece paradigmática tanto pela extensão - 13 páginas, vários autores - quanto pela proximidade das análises acadêmicas. Recheada de referências à "falência do Estado", "ausência do Estado", "apodrecimento da polícia", etc., como conclusões sobre a ineficiência dos órgãos públicos (inclusive, mas não apenas, da polícia) e seu "descaso" para com as regiões de moradia da pobreza urbana, a mencionada relação causal ali aparece de forma sintética e explícita: "A ordem desertou a favela (sic). (...) A 
debandada dos serviços básicos rendeu Vigário Geral aos traficantes" (p. 29). Cf. Silva (1995).

15 Outra condição de possibilidade, que diz respeito às bases materiais de reprodução da violência urbana, é sua associação com o tráfico de drogas e com o acesso a tecnologias cada vez mais sofisticadas (armamentos) que este permite. Esta, porém, não me parece ser uma relação necessária, como em geral é considerada; em princípio, as práticas definidas como violência urbana podem ligar-se a qualquer outro suporte que garanta continuidade ao longo do tempo. (Neste sentido, a "descriminação" da produção e uso de drogas pode dificultar a reprodução da violência urbana, mas não é garantia de sua eliminação).

16 É justamente este aspecto essencial que a interpretação dominante, ao abandonar a representação da violência urbana como parte integrante de seu objeto, deixa de captar.

17 Neste ponto, talvez seja útil lembrar que esta é uma argumentação típicoideal, que empurra para seus limites lógicos os aspectos destacados para a análise e, portanto, não existe, em sua pureza, na realidade.

18 É provavelmente esta característica fundamental que, desapercebida, muitas vezes leva o observador a definir como gratuitos e inexplicáveis (ou explicáveis como puro sadismo, perversão, patologia de natureza psicológica) inúmeros atos de força muito explorados pela mídia.

19 Este pode ser o caso, por exemplo, da recuperação pelos criminosos de categorias religiosas, como "diabo", por exemplo, que precisariam ser melhor situadas no contexto da sociabilidade violenta. Identificações com o diabo, relativamente comuns na retórica dos criminosos, podem indicar uma adesão a valores religiosos, negando, pelo menos em parte, o argumento que venho desenvolvendo. Mas também podem indicar o "empréstimo" de uma categoria disponível para formular a auto-imagem dos "portadores" da violência urbana, traduzindo o mal representado pelo diabo na esfera religiosa em força autônoma, princípio de organização da forma de vida que eles instituem. Se este for o caso - ponto que só a pesquisa pode elucidar -, então ao invés de simples inversão, como em geral se acredita, tratar-se-ia de ressignificação

20 A partir de um enquadramento muito diferente do meu, de certa forma Caldeira (2000), em sua discussão da relação entre crime, segregação e cidadania, incorpora a dimensão espacial das questões aqui tratadas.

Abstract: The essay analyses one of the social organizations forms of force relations that are legal and administratively defined as violent criminality, such its appears in the big cities, specially in Rio de Janeiro. The proposed approach implies to consider the relation between symbolic production and certain social practices in its 
concrete and immediate singularity. In terms of argumentation, the text, when draws a violent sociability notion, tries to capture from the criminal practices the nature and the meaning of the radical transformation of social relations quality. The sociological production has had enormous difficulties to comprehend those changes.

Key-words: violent sociability, violent criminality, urban violence as social representation.

\section{Referências bibliográficas}

ADORNO, Sérgio. A criminalidade urbana no Brasil: um recorte temático. BIB Boletim Informativo e Bibliográfico de Ciências Sociais, Rio de Janeiro, v. 35, n. 1, p. 24. 1993.

CALDEIRA, Teresa Pires do Rio. Cidade de muros: crime, segregação e cidadania em São Paulo. São Paulo: Ed. 34, EDUSP, 2000.

COELHO, Edmundo Campos. A oficina do diabo: crise e conflitos no sistema penitenciário do Rio de Janeiro. Rio de Janeiro: Espaço e Tempo, IUPERJ, 1987.

A criminalização da marginalidade e a marginalização da criminalidade. Revista de Administração Pública, v. 12, n. 2, p.13961, abr./jun. 1978.

GIDDENS, A. Política, Sociologia e teoria social. São Paulo: Unesp, 1997.

LIMA, Roberto Kant de; MISSE, Michel; MIRANDA, Ana Paula M. Violência, criminalidade, segurança pública e justiça criminal no Brasil: uma bibliografia. BIB Revista Brasileira de Informação Bibliográfica em Ciências Sociais, Rio de Janeiro, n. 50, 2. ${ }^{\circ}$ sem. 2000.

LINS, Paulo. Cidade de Deus. Rio de Janeiro: Companhia das Letras, 1997.

SILVA, Luiz Antonio Machado da. A (des)organização do trabalho no Brasil urbano. São Paulo em Perspectiva, v. 4, n. 3/4, p.2-5, jul./dez. 1990.

. Um problema na interpretação da criminalidade urbana violenta. Sociedade e Estado, n. 2, 1995.

PERALVA, Angelina. Violência e democracia: o paradoxo brasileiro. São Paulo: Paz e Terra, 2000.

SANTOS, Wanderley Guilherme dos. Cidadania e justiça. Rio de Janeiro: Forense, 1979.

ZALUAR, Alba. A máquina e a revolta. São Paulo: Brasiliense, 1985. 